\title{
DERECHOS HUMANOS, RELATIVISMO Y PROTECCIÓN JURÍDICA DE LA MORAL EN EL CONVENIO EUROPEO DE DERECHOS HUMANOS
}

1 Convenio Europeo de Derechos Humanos puede definirse como una garantía internacional de protección de ciertos derechos humanos. El rasgo principal que ha distinguido al Convenio Europeo de Derechos Humanos (a partir de ahora: $\mathrm{CEDH}$ ) radica en que los Estados Partes del Tratado asumen obligaciones que pueden ser exigidas por los otros Estados contratantes, y también por los particulares. Por otro lado, el CEDH trata de lograr un mayor grado de integración de los sistemas jurídicos de los diferentes Estados miembros mediante una normativa que, especialmente en materia de derechos humanos, pretende convertirse en un «orden europeo común». En la consecución de este objetivo la existencia del Tribunal Europeo de Derechos Humanos juega un papel destacado, ya que emite decisiones obligatorias para los Estados Miembros.

Frente a las clásicas positivizaciones de derechos humanos efectuadas en este siglo, el CEDH ha incorporado mecanismos de protección de los derechos humanos novedosos y efectivos y que han provocado que una parte de la doctrina haya calificado al Convenio como

«el instrumento más acabado y eficaz de protección de los derechos del hombre, precisamente por establecer remedios procesales ${ }^{2} \gg$.

${ }^{1}$ En especial destacan tres mecanismos: 1) la instauración de un sistema de garantía colectiva; 2) la instauración del derecho de demanda individual; 3) la instauración de un sistema de protección exclusivo. Véase: Fernández Sánchez, Pablo Antonio: Las obligaciones de los Estados en el marco del Convenio Europeo de derechos humanos. Ministerio de Justicia, Centro de Publicaciones, Madrid, 1987, pág. 28.

${ }^{2}$ Pastor Ridruejo, José Antonio: «El Convenio Europeo de los Derechos del Hombre y el "ius cogens" internacional»; en VV. AA.: Estudios en homenaje al profesor Miaja de la Muela; Madrid, 1979, pág. 582. 
Desde una perspectiva jurídica, no cabe duda de que el prestigio alcanzado por el CEDH se debe por un lado, a la estructura y funcionamiento de sus instituciones y, por otro lado, al grado de protección jurídica de los derechos humanos.

En relación a la protección de los derechos humanos llevada a cabo por el Convenio y el Tribunal Europeo de Derechos Humanos me propongo analizar en este trabajo (I) el carácter universal de los derechos humanos. Pero a pesar de esta propiedad, el propio Convenio introduce limitaciones a los derechos humanos. Uno de estos límites es la «protección de la moral». En (II) trataré de mostrar el significado que la jurisprudencia del Tribunal atribuye a esta cláusula. Por último, examinaré dos consecuencias de índole moral que pueden extraerse del significado y aplicación de esta cláusula: (III) el relativismo moral y (IV) la justificación de la imposición de la moral a través del Derecho.

\section{El carácter universal de los derechos humanos}

Los derechos humanos han recibido históricamente diferentes conceptos y fundamentaciones ${ }^{3}$. La concepción liberal de los derechos humanos ha constituido el principal fundamento de las positivizaciones internacionales producidas durante este siglo ${ }^{4}$. Los redactores del Convenio no manifestaron explícitamente que esta fuese la concepción sobre la que descansaban los derechos humanos. Sin embargo, la doctrina internacionalista tiende a destacar su importancia ${ }^{5}$.

Al margen de la discusión acerca de que teoría moral haya sido el principal fundamento de los derechos humanos del Convenio, lo que

${ }^{3}$ Ver Pérez Luño, A. E.: Derechos humanos, Estado de Derecho y Constitución. Tecnos, Madrid, 1984, págs. 132-187.

${ }^{4}$ Donnelly, Jack: Universal Human Rights in Theory and Practice; Cornell University Press, Ithaca-London, 1989, pág. 71. En este punto es necesario matizar que es simplista reducir el liberalismo a una única versión. Un breve pero explicativo análisis de las alternativas liberales puede encontrarse en la introducción que realiza M. Sandel a la recopilación de artículos incluidos en el volumen Liberalism and its Critics. Basil Blackwell, Oxford, 1984.

${ }^{5}$ Respecto a este último, puede verse que el primer artículo se dirige a reconocer a toda persona el derecho a la libertad y a la seguridad, para después proteger la vida (art. 2), prohibir la tortura (art. 3), la esclavitud (art. 4), la retroactividad de las disposiciones jurídicas (art. 7), garantizar «el proceso justo» (art. 6), el respeto de la vida privada y familiar, el domicilio y la correspondencia (art. 8), la libertad de pensamiento, de conciencia y de religión (art. 9), de expresión (art. 10), de reunión pacífica, y la libertad de asociación (art. 11), de contraer matrimonio (art. 12), y en último lugar, aunque sin mencionarlo explícitamente, el principio de igualdad (art. 14). 
interesa destacar son los caracteres que usualmente se le atribuyen a aquéllos. En este sentido, existe un consenso generalizado en la teoría ética en considerar a los derechos humanos como universales, absolutos e inalienables. Pero a efectos de este trabajo basta acentuar el carácter universal de los derechos humanos, pues es la propiedad que resultará afectada por la cláusula limitativa que protege a la moral.

La universalidad de los derechos humanos hace referencia a los titulares de esos derechos. En uno de sus posibles sentidos, la universalidad es una característica que señala que los derechos humanos se dirigen a una clase de beneficiarios que debe determinarse materialmente. Esta clase está integrada por todos los seres humanos y nada más que por seres humanos. En sentido contrario, la posesión de los derechos humanos no puede limitarse a subclases de individuos humanos o extenderse más allá de la especie humana:

«La pertenencia a la especie humana es condición necesaria y suficiente para gozar de los derechos en cuestión, en tanto que otras propiedades -raza, sexo, inteligencia, actos cometidos o padecidos, etc.- son irrelevantes» ${ }^{6}$.

La noción de universalidad de los derechos humanos implica su adscripción a todos los individuos al margen de su circunstancia vivencial o contextual, lo cual supone la superación de las moralidades positivas en favor de una ética común y general, pues todos los seres humanos se consideran agentes morales ${ }^{7}$.

Esta concepción de la universalidad de los derechos humanos entraña varias consecuencias. En primer lugar, significa que su concesión toma como única propiedad relevante la circunstancia de que sus beneficiarios pertenecen a la especie humana. De aquí se infiere que todos los hombres poseen un título igual a la posesión de los derechos humanos en la medida en que todos exhiben que esa propiedad relevante en el mismo grado.

En segundo lugar, supone afirmar que los derechos humanos se poseen al margen de si el beneficiario está dentro de un sistema jurídico positivo. Como dice Laporta,

${ }^{6}$ Nino, C. S.: Ética y derechos humanos. Ariel, Barcelona, 1989, pág. 41. Ver también Meyers, Diana: Los derechos inalienables. Alianza Editorial, Madrid, 1988 [Columbia University Press, 1985]. Trad. E. Beltrán, pág. 13.

${ }^{7}$ Laporta, Francisco: «Sobre el concepto de los derechos humanos», DOXA, 5, 1988, pág. 
«hay una imposibilidad conceptual en afirmar simultáneamente que los derechos humanos son universales y que son producto del orden jurídico positivo, porque la condición de sujeto de un sistema jurídico excluye la noción de universalidad de que estamos hablando» ${ }^{8}$.

Ésta es la razón por la cual esta concepción sostiene que los derechos humanos son derechos morales, porque su lugar natural de ubicación no es un sistema jurídico positivo, sino el ámbito de la ética.

En tercer lugar, la noción de derecho moral universal parece implicar que su posesión también es independiente de condicionamientos institucionales o de «rol». Los derechos humanos actúan fuera de cualquier vinculación con las instituciones éticas concretas que existen en una moralidad positiva o en un sistema jurídico positivo.

Pues bien, a pesar de que la universalidad es una propiedad definitoria de los derechos humanos, los redactores del Convenio introdujeron algunas cláusulas que limitaban esta pretensión. Una de estas cláusulas es la «protección de la moral» que ha sido utilizada para restringir la universalidad de los derechos humanos en aras de la protección de concepciones morales positivas sostenidas en comunidades determinadas.

\section{Los límites a los derechos humanos en el Convenio: «La protección de la moral»}

Los derechos humanos que recoge el CEDH constituyen el aspecto central de la pretensión de crear un orden europeo. Por ello, una primera lectura del Convenio parece mostrar que el alcance de los derechos humanos va aumentando con el tiempo merced a la inclusión de nuevos derechos. Otra impresión que se obtiene del Convenio es que los derechos humanos parecen tener un significado y alcance propio e independiente de las eventuales interpretaciones que realicen órganos estatales. Aquí juega un papel central el TEDH que es el órgano supremo en lo concerniente a la aplicación e interpretación del Convenio, y que ostenta el control de la coherencia de los derechos humanos en los diferentes Estados.

Sin embargo los redactores del Convenio no pensaron que los derechos humanos constituyeran una categoría absoluta, sino que por el contrario, pocos derechos se libran de algún tipo de res-

\footnotetext{
${ }^{8}$ Laporta, Francisco: «Sobre el concepto de los derechos humanos», op. cit., págs. 32-33.
} 
tricción ${ }^{9}$. Estas restricciones se imponen mediante diversos procedimientos ${ }^{10}$ y cuyo análisis excede las pretensiones de este trabajo, por lo que únicamente se examinará uno de ellos, la cláusula «la protección de la moral».

La expresión «protección de la moral» forma parte del conjunto de «conceptos jurídicos indeterminados» que aparecen en el Convenio. Sus redactores no ofrecieron ningún tipo de explicitación de su significado. El Tribunal tampoco ha sabido (o querido) definirla con exactitud en las pocas sentencias donde ha abordado su discusión. Sin embargo, a pesar de la falta de claridad que rodea a este concepto, el Tribunal lo ha usado para restringir derechos humanos. Por ello, resulta interesante tratar de reconstruir el significado que la jurisprudencia del Tribunal ha otorgado a esta expresión.

En una primera aproximación a dicho concepto se puede afirmar que el Tribunal interpreta el término «moral» como el conjunto de creencias, actitudes y standards morales compartidos por la mayor parte de ciudadanos de una sociedad determinada:

«Esta última [la protección de la moral] implica la protección del ethos moral o de los standards éticos de la sociedad en su conjunto» ${ }^{11}$.

${ }^{9}$ Ver Ganshof Van Der Meersch, Walter J.: «Reflexions sur les restrictions a l'exercice des droits de l'homme dans la jurisprudence de la Cour européenne de Strasbourg» en Bernhardt. R.; Geck W. K.; Jaenicke F.; Steinberger, H.: Völkerrecht als Rechtsordnung Intemationale Gerlchtsbarkeit Menschrechte. Festschrift für Hermann Mosler. Springer Verlag, Berlin-Heidelberg-New York, 1983 , págs. 263 y ss.

${ }^{10}$ Estos procedimientos son: 1) límites a determinados derechos; 2) el derecho de derogación de las obligaciones del Convenio en caso de guerra u otro peligro público que amenace la vida de la nación (art. 15); 3) la prohibición de interpretar los derechos humanos con la finalidad de reducirlos o destruirlos (art. 17).

${ }^{11}$ Caso Dudgeon, sentencia de 22 de octubre 1981, par. 47. En dicho caso, el apelante afirmaba estar siempre bajo la amenaza, en virtud de una antigua legislación de Irlanda del Norte, de persecuciones penales a causa de su comportamiento homosexual, y eso en desprecio del art. 8 de la Convención Europea de Derechos Humanos que garantiza el derecho al respeto de la vida privada. Una legislación que databa de 1861 y 1885, así como los precedentes jurisprudenciales del Common Law condenaban esas prácticas. Según esta legislación cualquier individuo puede entablar una acción pública para perseguir un delito homosexual, quedando a disposición de las autoridades irlandesas la facultad de asumir la dirección del proceso. Según el apelante, sus quejas se basan sobre todo en que tanto el derecho en vigor en Irlanda del Norte como la investigación policial que se realizó en su domicilio constituyen una interferencia injustificada de su derecho al respeto de la vida privada con la consiguiente violación del art. 8 de la Convención. 
En la sentencia del caso Handyside ${ }^{12}$ el Tribunal manifestó que «la protección de la moral» debe ser utilizada cuando el bien que ella protege está por encima del bien que garantiza un derecho humano. Además concluyó que el dato relevante para dotar de significado al término «moral» debe ser las concepciones éticas que sostienen los miembros de una sociedad:

«a pesar de la diversidad y la evolución constante de las concepciones éticas y educativas en el Reino Unido, los magistrados ingleses estuvieron en su derecho de creer en la época, en el ejercicio de su poder de apreciación, que el Schoolbook tendría repercusiones nefastas sobre la moralidad de muchos niños y adolescentes que lo leyeran ${ }^{13}$.

En el asunto Dudgeon, el Tribunal discutió la legitimación del Gobierno de Irlanda del Norte para proteger legalmente la moral frente a los derechos y libertades de los individuos. En otras palabras, la tensión se produjo entre la protección de la sociedad en su conjunto en lo que concierne a sus patrones morales o éticos que podrían verse afectados en caso de despenalización de la homosexualidad, y los derechos de los individuos que sufren persecución penal debido a sus inclinaciones sexuales. El temor de las autoridades norirlandesas fue que una autorización jurídica de la conducta homosexual masculina en Irlanda del Norte tendería a erosionar los standards morales existentes ${ }^{14}$.

${ }^{12}$ Caso Handyside (sentencia de 7 de diciembre de 1976), el recurrente M. R. Handyside, propietario de una editorial publica en 1971 el libro The little Red Schoolbook para el uso de los escolares. El libro, de origen danés, también había sido publicado en diferentes países europeos (Bélgica, Finlandia, Francia, Alemania, Grecia, etc.). El libro recibió una notable publicidad, y poco tiempo después, y tras una campaña periodística en contra de su contenido, el Director de Public Prosecutions ordenó la apertura de una encuesta de la que surgió la orden de registro de los locales ocupados por la editorial del Sr. Handyside. En virtud de lo dispuesto en el art. 3 de la Ley 1959-1964 sobre publicaciones obscenas se procedió al secuestro de 1.609 ejemplares del libro. El Tribunal de instancia condenó al Sr. Handyside por ser culpable de dos infracciones a la Ley sobre publicaciones obscenas. A pesar del recurso, los tribunales superiores confirmaron la sentencia del Tribunal de instancia.

Ver un análisis de este caso en Higgins, Rosalyn: «The European Convention on Human Rights» en Shestack, Jerome J: The Jurisprudence of Human Rights, op. cit., pág. 532 y ss.

${ }^{13}$ Caso Handyside (sentencia de 7 de diciembre de 1976).

${ }^{14}$ Caso Dudgeon (sentencia de 22 de octubre 1981), par. 47. El Tribunal se expresó de la siguiente manera:«Se comprende mejor hoy el comportamiento homosexual que en la época de la adopción de esta legislación y se manifiesta mayor tolerancia: en la mayoría de los Estados miembros del Consejo de Europa se ha dejado 
Por otro lado, el Tribunal también se manifestó sobre un punto importante de la protección de los derechos humanos en su relación con la protección de la moral, y es la distinta valoración que se ha de prestar a la protección de la moral según la sociedad de que se trate:

«el hecho de que medidas similares no se consideren necesarias en otras partes del Reino Unido o en los Estados miembros del Consejo de Europa no significa que no puedan ser necesarias en Irlanda del Norte. Cuando existen disparidades culturales entre las comunidades que residen en el mismo Estado, el Gobierno debe hacer frente a las diferentes exigencias, tanto morales como sociales» ${ }^{15}$.

El Gobierno del Estado respectivo, por lo tanto, está legitimado para apreciar con mayor exactitud la importancia y extensión de las prácticas y convicciones morales vigentes en su sociedad, no sólo porque pueda haber diversidades culturales en la sociedad, sino también porque tienen

«un contacto directo y continuo con las fuerzas vitales de sus países... están en principio en una posición mejor que el juez internacional para dar una opinión sobre el contenido exacto de dichas exigencias» ${ }^{16}$.

En clara extensión de esta doctrina, el Tribunal atribuyó al Gobierno la facultad de apreciar el clima moral de Irlanda del Norte en lo que se refiere a los temas sexuales. El Tribunal opinó que

«en lo que afecta a los temas sexuales... es uno de los asuntos que las autoridades nacionales pueden legítimamente tener en cuenta a la hora de ejercitar sus facultades discrecionales» ${ }^{17}$.

En definitiva se pueden resumir las consideraciones que ha emitido el Tribunal sobre esta materia en los cuatro puntos siguientes:

de creer que las prácticas de este tipo apelan por ellas mismas una represión penal, la legislación interna ha experimentado en este punto una evolución que el Tribunal no podría descuidar...». Finalmente, el TEDH dictó sentencia en el sentido de que el apelante «habría sufrido» un atentado (no justificado por la protección de la moral) a su derecho al respeto a la vida privada.

${ }^{15}$ Caso Dudgeon (sentencia de 22 de octubre 1981), par. 47.

${ }^{16}$ Caso Handyside (sentencia de 7 de diciembre de 1976), par. 48.

${ }^{17}$ Caso Handyside (sentencia de 7 de diciembre de 1976), par. 48. 
1) La protección de la moral se centra básicamente en los standards morales que comparte una sociedad en general ${ }^{18}$.

2) El Tribunal se reserva en última instancia el control de la congruencia entre esta excepción y los derechos humanos, por lo que existe una supervisión europea de la actuación de las autoridades estatales. Sin embargo, el propio Tribunal ha reconocido en numerosas ocasiones que quien se encuentra mejor situado para captar la moral social son las autoridades estatales. La inexistencia de una noción europea uniforme de moral ha provocado que el Convenio confíe a cada Estado el cuidado de asegurar el goce de los derechos y libertades que se recogen en el Tratado.

3) Las exigencias de la moral varían en el tiempo y en el espacio debido principalmente a la rápida e importante evolución de las costumbres, creencias y opiniones sobre la materia. Por esta razón, son los propios legisladores de los Estados los que están en una mejor posición para captar el contenido de las exigencias de la moral social. Y de manera especial, están más capacitados para valorar la necesidad de que los derechos humanos sean restringidos en favor de la protección de la moral.

4) Las consideraciones precedentes han conducido al Tribunal a renunciar al intento de precisar el contenido de la expresión «moral» ${ }^{19}$.

En definitiva, toda esta argumentación ha llevado al Tribunal a limitar el alcance de los derechos humanos en virtud de «la protección de la moral», cláusula cuyo contenido es configurado por las respectivas autoridades nacionales. Éstas toman en consideración a dicho efecto, el conjunto de creencias y valores existentes en su sociedad.

Sin embargo, esta posición del Tribunal acerca del significado de la clausula «protección de la moral» no está exenta de problemas. A continuación se va a tratar de mostrar que esta posición puede encuadrarse en una teoría ética discutible: el relativismo.

\section{La «protección de la moral» y el relativismo}

Las tesis del Tribunal acerca del término «moral» permiten concluir que su posición teórica es el relativismo moral. Según esta

${ }^{18}$ Caso Müller y otros (sentencia de 24 de mayo 1988). par. 30.

${ }^{19}$ Caso Müller y otros (sentencia de 24 de mayo 1988), par. 35. 
teoría ética, las reglas morales y las instituciones sociales evidencian una notable variabilidad cultural e histórica. Sostiene además, que hay sistemas morales diferentes y hasta discordantes, pero que todos ellos son igualmente válidos como mecanismos de regulación de la vida de los individuos.

El problema central que surge de esta concepción que parece acoger el Convenio y el Tribunal estriba en la contraposición con el universalismo de los derechos humanos, es decir, ¿cómo pueden compatibilizarse las pretensiones del relativismo moral y la universalidad de los derechos humanos? Un análisis adecuado de la controversia entre el relativismo y los derechos humanos requiere previamente distinguir los distintos niveles de moralidad en que se puede situar el relativismo: el nivel socio-cultural, normativo, y metaético. El relativismo ético socio-cultural sostiene una tesis de carácter empírico fundada en investigaciones de antropólogos, sociólogos y psicólogos. Constata el hecho de que las personas y los distintos grupos sociales difieren en sus creencias morales. No hay un único sistema de creencias morales compartidas por todas las sociedades. Más bien al contrario, puede realizarse un juicio fáctico que muestre la variabilidad de concepciones morales que existen en las diferentes sociedades humanas. La explicación de esta diversidad de creencias morales se basa en los diferentes condicionamientos sociales y culturales que rodean a los diferentes grupos o sociedades.

El relativismo normativo se sitúa en el nivel prescriptivo de la ética y supone que en cada caso la corrección de cualquier acto o bondad de una cosa para un miembro de una cultura dada esta justificado por referencia a lo que de hecho piensa que es correcto ${ }^{20}$. En este sentido, parece confundirse con el subjetivismo en alguna de sus versiones, en concreto con aquella que afirma que los juicios morales enuncian las actitudes de quien los profiere. Y no se puede decir que la opinión o sentimiento moral de un individuo es más correcto que el de los demás. Personas diferentes tienen diferentes sentimientos, y esto es lo máximo que se puede decir de sus juicios morales ${ }^{21}$. Por último, el relativismo metaético se encuadra en el estudio teórico-conceptual. Esta modalidad de relativismo puede adoptar dos versiones: el subjetivismo y el nodescriptivismo. Desde el subjetivismo (metafísico) se afirma que los juicios morales describen actitudes

${ }^{20}$ Esto supone que nadie debe dirigir juicios morales a otros individuos que tengan valores sustancialmente diferentes, o intentar conformarlo a los valores que uno sustenta. Wong, David: «Relativism» en Singer, Peter (ed.): A Companion to Ethies. Blackwell. Oxford, 1993, pág. 443.

${ }^{21}$ Rachels, James: «Subjectivism» en Singer, Peter (ed.): A Companion to Ethics. Blackwell. Oxford, 1993, pag. 432. 
del hablante. Como señala Williams, los enunciados morales del subjetivismo tales como «Mi actitud hacia esto es...», serían simplemente observaciones autobiográficas ${ }^{22}$. Sostiene la validez de la tesis empírica del relativismo cultural y añade que los juicios morales contrapuestas acerca del mismo acto son igualmente válidos. No puede haber juicios de valor que sean verdaderos $\mathrm{u}$ objetivamente justificables independientemente de la cultura específica.

Una vez expuesta las diferentes variantes de relativismo se está en disposición de analizar con mayor precisión la posición relativista del Tribunal. En primer lugar, no cabe duda de que el Tribunal manifiesta una postura coincidente con la tesis central del relativismo cultural: admite la diversidad cultural como origen de las diferentes valoraciones que muestran las distintas sociedades en cuestiones de índole moral (inexistencia de una moral europea uniforme). Las creencias mayoritariamente compartidas por los integrantes de una sociedad son las que dan significado (y por tanto, definen) a los derechos que aceptan los Estados. El corolario de esta concepción es que cada Estado miembro del Convenio puede modificar y restringir las pretensiones universalistas de los derechos humanos según sean las particularidades de su sociedad respecto a determinadas cuestiones de índole moral.

Por otro lado, el Tribunal también asume el postulado básico del relativismo normativo: afirma que la corrección de un acto depende de lo que en esa sociedad se decida como tal. En otras palabras, la constatación de la diversidad cultural y de creencias éticas parece razón suficiente para justificar que las autoridades convaliden dichas creencias. Cada sociedad se caracteriza por mantener criterios, creencias y principios morales propios, siendo los órganos estatales los más adecuados para juzgarlos. La justificación última de esta tesis relativista es que no hay una noción europea de moral, y además estas diferentes morales sociales son igualmente válidas.

La moral, tal y como la entiende el Tribunal, es un concepto cuyo significado puede descomponerse mediante un análisis empírico, en creencias y principios compartidos por la mayoría de miembros de la sociedad. Por otro lado, esas creencias y principios suelen cambiar según el transcurso del tiempo. Por ello, el Tribunal juzga que las medidas de protección de la moral vigentes en otros países no pueden extenderse justificadamente a otras sociedades. Lo que se considera adecuado o necesario en una sociedad puede no serlo en otra, y no parece legítima la imposición de unos criterios sobre otros. La aceptación por parte del legislador europeo y del Tribunal de la clausula limitativa de los derechos humanos «protección de la

${ }^{22}$ Williams, Bernard: Introducción a la ética. Cátedra, Madrid, 1987 [1972]. Trad. M. Jiménez Redondo, pág. 29. 
moral» y del relativismo que lleva implícita, presenta algunos problemas. El examen de estos último puede realizarse en dos niveles: uno filosófico (crítica del relativismo en sus diversas variantes), y otro basado en las consecuencias prácticas que genera el uso de la «protección de la moral». En cuanto al primer punto será suficiente remitirse a las conocidas críticas que se han dirigido contra el relativismo en sus diversas variantes ${ }^{23}$.

Respecto a las consecuencias del relativismo defendido por el Tribunal es conveniente destacar los siguientes puntos. En primer lugar, la aplicación de la cláusula limitativa por parte de las autoridades tiene como resultado que no todos los ciudadanos de los Estados miembros de la Convención tienen los mismos derechos. Ésta es una implicación bastante obvia puesto que el ejercicio de la cláusula es una potestad que depende de los Estados y tiene validez únicamente para los sujetos miembros de su Derecho nacional. El contenido de la limitación a los derechos humanos no es idéntico en todos los Estados miembros de la Convención, sino que varía según la percepción de las respectivas autoridades.

En segundo lugar, se origina la existencia de situaciones contradictorias dentro del conjunto de normas que componen la Convención: ciertas situaciones de hecho serán permitidas en determinados Estados (en relación a lo establecido en las normas que recogen los derechos humanos), mientras que en otros Estados, las mismas situaciones de hecho pueden ser calificadas de prohibidas según la cláusula limitativa de la protección de la moral. Este resultado se refleja, por ejemplo, en la sentencia del caso Handyside de la que se extrae la conclusión de que en algunos países la publicación del Red book está permitida (Bélgica, Irlanda, etc.), pero en otros está prohibida, como es el caso del Reino Unido.

En tercer y último lugar, la interpretación que el propio Tribunal ha realizado de la cláusula «protección de la moral» conduce en último extremo a dejarle sin su función principal: dictar sentencias sobre casos conflictivos según unas disposiciones que configuran un pretendido «orden común europeo», es decir, las normas de derechos humanos. Pero estas normas reducen su ámbito de aplicación por la vigencia de aquella cláusula limitativa, cuyo significado y alcance queda en manos de la interpretación de las autoridades de cada Estado Parte del Convenio. La tarea del Tribunal se limita entonces a convalidar las decisiones apreciativas de dichas autoridades acerca de la moral positiva de su sociedad.

${ }^{23}$ Ver Rabossi, Eduardo: Estudios éticos. Cuestiones conceptuales y metodológicas. Universidad de Carabobo, Carabobo, 1971. Williams, Bernard: Introducción a la ética, op. cit.. Nino, Carlos: Ética y derechos humanos, op. cit. 


\section{La justificación de la protección de la moral a través del Derecho}

El segundo interrogante que plantea la expresión «protección de la moral» como límite de los derechos humanos tiene que ver con la justificación del castigo jurídico a aquellas conductas que son inmorales. En otras palabras, ¿está facultada la sociedad para imponer, mediante el Derecho, una moral?, ¿qué tipo de legitimidad puede alegar una autoridad jurídica que utiliza la coacción para restablecer una regla moral que ha sido transgredida?

Estos interrogantes han sido abordados por el Tribunal en alguna de las sentencias anteriormente aludidas: en el caso Dudgeon las autoridades norirlandesas hicieron uso de la legislación penal para sancionar, no la conducta o acción, sino únicamente, la inclinación sexual del Sr. Dudgeon. La justificación de la que se valieron señalaba que la homosexualidad atentaba contra las costumbres y la moral de la sociedad norirlandesa, y que su tolerancia produciría un resquebrajamiento irreversible del tejido social. Argumentos similares hicieron aparición en los casos Handyside y Müller.

El problema con que se enfrento el Tribunal en estas sentencias tenía ya una larga historia de debate en la filosofía moral. Los utilitaristas clásicos, J. Bentham y J. Stuart Mill, sostuvieron que el uso del Derecho como instrumento represivo sólo estaba justificado cuando un tercero había sido lesionado efectivamente. Carecía de justificación cuando el delito afectaba el código moral de la comunidad. A mediados de este siglo reapareció el problema con la crítica de Devlin $^{24}$ al informe «Wolfenden» (1957) sobre la regulación jurídica inglesa de la prostitución y la homosexualidad, cuyas tesis principales coincidieron con las ideas de los utilitaristas. El punto fundamental que se discutió en el informe fue el problema de la relación entre Derecho y moral, o en otras palabras, entre delito y pecado. Se trataba de responder a la pregunta de hasta dónde debe intervenir la coacción penal: ¿debe castigar las infracciones de la moral? La idea principal que defendía Devlin era que el Derecho debería castigar la inmoralidad. El interés por este tipo de tesis ha vuelto a aparecer después de un tiempo en el que han estado aletargadas. En efecto, como señalaba Nino, de nuevo el espectro de Hegel planea sobre el liberalismo kantiano. Los argumentos de Devlin han sido retomados por el comunitarismo, pero también han tenido su reflejo en algunas decisiones estatales y del propio TEDH.

${ }^{24}$ Devlin, Patrick: The Enforcement of Morals. Oxford University Press, London-New York-Toronto, 1965, pág. 11. 
Así pues, los argumentos de Devlin pueden descomponerse en las siguientes consideraciones $^{25}$. En primer lugar, en una sociedad existen patrones morales que la mayoría de la población excluye de la tolerancia y que impone a quienes disienten de ellos, como por ejemplo, la práctica de la monogamia. Una sociedad no puede sobrevivir a menos que algunos de sus patrones morales sean de ese tipo, porque para su vida es esencial cierto tipo de consenso moral. Las pautas morales constituyen una especie de cemento social que debe ser reforzado con la sanción jurídica oficial. Si el gobierno no impone el código moral imperante sobreviene un colapso de los frenos sociales y de las costumbres basadas en la convención compartida.

El orden y la cohesión sociales sufren un deterioro. Esto es lo que llama la «tesis de la desintegración». Toda sociedad tiene derecho a preservar su propia existencia y, por consiguiente, derecho a reclamar alguna forma de conformidad.

En segundo lugar, si la sociedad tiene un derecho como el que se acaba de aludir, entonces tiene la facultad de usar las instituciones y sanciones de su Derecho Penal para imponer ese derecho:

«la sociedad puede utilizar el derecho para preservar la moralidad de la misma manera que lo usa para preservar cualquier otra cosa, si es esencial para su existencia».

La justificación de la autodefensa jurídica de la sociedad frente a conductas erosionadoras o dañosas del entramado moral, también ha sido recogida por el TEDH:

«En particular, las actitudes éticas hacia la conducta homosexual masculina

en Irlanda del Norte y la preocupación de que cualquier relajación en el derecho tendería a erosionar los standards morales existentes...».

Este tipo de opiniones son recogidas con mayor énfasis por algunos de los votos particulares. Por ejemplo, el juez Zelcia manifiesta en el voto particular de la sentencia citada que:

«La mayoría en una sociedad democrática está también facultada, de acuerdo con los artículos 8, 9 y 10 del Convenio

${ }^{25}$ Dworkin, Ronald: «Libertad y moralismo» en Los derechos en serio. Ariel, Barcelona, 1989. Antes publicado bajo el título «Lord Devlin’s Enforcernent of morals» en Yale Law Journal, 75, 1966, pág. 352.

${ }_{26}$ Devlin, Patrick: The Enforcement of Morals, op. cit., pág. 11

${ }^{27}$ Caso Dudgeon (sentencia 22 de octubre de 1981). Considerando 61. B.JC, pág. 745. 
y el artículo 2 del Protocolo, número 1, para que se respeten sus creencias religiosas y morales y, por tanto, en condición de enseñar y llevar a la mentalidad de sus hijos las convicciones concordantes con sus principios religiosos y morales ${ }^{28}$.

Ahora bien, el problema consiste en determinar qué clase de actividad inmoral debería ser prohibida por el Derecho. En este punto, Lord Devlin y el Tribunal vuelven a coincidir. Según el jurista inglés, el criterio que debe ser utilizado es el del «hombre razonable» («the man on the Clapham omnibus»):

«La inmoralidad..., para los propósitos del Derecho, es lo que cualquier persona razonable considera inmoral»

Por su parte el Tribunal reconoce que el criterio para definir la moralidad vigente de la población de una sociedad dada debe remitir también al «hombre razonable»:

«las concepciones de la moral sexual han cambiado estos últimos años. No obstante, después de examinar los cuadros objeto del litigio, cree que no les faltaron razones a los tribunales competentes para considerarlos "de naturaleza susceptible de herir brutalmente", por el realce dado a la sexualidad en alguna de sus formas más crudas, "la decencia sexual de las personas de sensibilidad normal" 29 ».

Devlin sostiene que cuando los legisladores deben decidir si una conducta es inmoral, y por tanto, punible, deben hacerlo según las pautas del consenso que haya alcanzado la comunidad. Esto es lo que exige el principio democrático. Nada alejado de esta concepción se encuentra el Tribunal cuando justifica que el gobierno del Reino Unido omitiera la modificación de legislación penal antihomosexual sobre la base de un

«sentimiento fuertemente arraigado en Irlanda del Norte contra el cambio propuesto $\mathrm{y}$, en particular, por el vigor de la opinión de que sería enormemente peligroso para el entramado moral de la sociedad de Irlanda del Norte ${ }^{31}$.

\footnotetext{
${ }^{28}$ Caso Dudgeon (sentencia 22 de octubre de 1981). Voto particular del juez Zekia. BJC, pág. 747.

${ }^{29}$ Devlin, Patrick: The Enforcement of Morals, op.cit., pág. 15.

${ }^{30}$ Caso Müller y otros, (sentencia 24 de mayo de 1988), Considerando 36. BJC, pág. 1513.

${ }^{31}$ Caso Dudgeon (sentencia 22 de octubre de 1981). Considerando 61. BJC. pág. 743.
} 
Según Devlin, la sociedad tiene un derecho ilimitado a legislar contra la inmoralidad y su justificación es bien clara: la pervivencia de la propia sociedad. No es extraño por ello, que acabe comparando el castigo del vicio con el castigo de la traición. Esto se advierte con claridad en el siguiente párrafo, a pesar de su extensión:

«La sociedad tiene derecho a protegerse a través de sus leyes de los peligros, bien procedan de dentro, bien desde fuera. Aquí pienso de nuevo que el paralelo con la política es legítimo. La ley de la traición está dirigida directamente contra la prestación de ayuda a los enemigos del rey y contra la sedición desde el interior. La justificación de esto reside en que es necesario un gobierno establecido para la existencia de la sociedad, y por tanto se debe proteger la seguridad de aquel de ataques violentos. Una moral establecida es tan necesaria como un buen gobierno para el bienestar de la sociedad. La desintegración sobrevendrá cuando no se observe moralidad compartida alguna, y la historia enseña que la perdida de los lazos morales es, en muchas ocasiones, el primer paso hacia la desintegración, de manera, que la sociedad está justificada para tomar las medidas con el fin de proteger su código moral, de la misma forma que lo hace para preservar su gobierno y otras instituciones esenciales. La supresión del vicio es asunto del Derecho, tanto como lo es la supresión de las actividades subversivas. No es más posible definir una esfera de moralidad privada que definir una esfera de actividad subversiva privada. No hay límites teóricos al poder del Estado para legislar contra la traición y la sedición, como creo que tampoco pueden haber límites teóricos a la legislación contra la inmoralidad» ${ }^{32}$.

Las tesis de Lord Devlin provocaron multitud de réplicas entre las que destacaron las del profesor H. L. A. Hart, y que parecían clausurar el debate. Sin embargo, en la década de los ochenta surgen de nuevo con fuerza los planteamientos favorables al castigo jurídico de las conductas inmorales. Tales planteamientos no sólo han sido acogidos por algunos filósofos (los comunitaristas), sino también por las autoridades estatales de algunos países. Quizá el caso más famoso es Bowers vs. Harvick (1986) en el que el Tribunal Supremo estadounidense se manifestó favorable al mantenimiento de la ley penal de Georgia que tipifica el delito de sodomía ${ }^{33}$. Pero también en

${ }^{32}$ Devlin, Patrick: The Enforcement of Morals, op. cit., págs. 134.

${ }^{33}$ El debate sobre esta cuestión fue el motivo del monográfico de la Californian 
Europa existen ejemplos de este tipo de postura. Así en el asunto Norris (6/1987) el TEDH examinó la legislación irlandesa («Offences against the Person Act», 1861) que penalizaba ciertos actos homosexuales realizados consentidamente en privado entre adultos ${ }^{34}$.

Los argumentos presentados por Hart todavía son válidos. El autor inglés pone en cuestión la tesis central de esta corriente de pensamiento: la preservación de la moralidad social constituye algo bueno en sí mismo. En relación a esta cuestión, Hart presenta los siguientes contrargumentos:

a) No parece nada claro cuál puede ser el valor de obtener conformidad con la moral, no a través del convencimiento sino de la compulsión. Según Hart, la atribución de valor a la conducta conforme, con independencia de los motivos y las consecuencias que la motivan, pertenece no a la moral sino al tabú ${ }^{35}$.

b) Esta corriente de pensamiento presupone que hay un consenso moral en la sociedad, lo cual parece bastante objetable en las sociedades modernas donde se produce una diversidad considerable de ideas, costumbres y de creencias. Precisamente uno de los argumentos fuertes del liberalismo parte de la base de este dato fáctico frente al que hay que oponer el principio de neutralidad como mecanismo de resolución de los conflictos entre las distintas concepciones del bien. Aunque con la salvedad de que lo correcto es un prerrequisito de la concepción del bien que se realice.

c) La moral vigente en una sociedad puede ser considerada aberrante, por lo que sería difícil justificar que su protección es una dato valioso ${ }^{36}$.

d) La dificultad conceptual para aceptar el criterio de identificación de lo que es inmoral basado en lo que la gente

Law Review de 1989 (77), en el que discutían la justificación de dicha resolución autores como Dworkin y Sandel.

${ }^{34}$ Otros recientes casos en los que el Tribunal examina la legitimidad de legislaciones y decisiones estatales basadas en la protección de la moral son las siguientes: Affaire Open Door et Dublin Well Woman c. Irlanda en la que las demandantes cuestionan la orden del Tribunal Supremo irlandés que prohibía a dichas sociedades aconsejar e informar a las mujeres embarazadas sobre las posibilidades de abortar en el extranjero. Según el Gobierno irlandés su legislación tenía por objetivo la protección de los derechos del nasciturus, pero también, la protección de la moral. 57.

${ }^{35}$ Hart, H. L. A.: Law, Liberty and Morality. Oxford University Press, London, 1963, pág.

${ }^{36}$ Hart, H. L. A.: Law, Liberty and Morality, op. cit., pág. 19. 
«siente» como peligroso. «Lo sentido como peligroso» no necesariamente tiene que coincidir con aquello que es efectivamente peligroso para la preservación de la sociedad. El sentimiento puede suministrar datos que permitan describir el estado de creencias y actitudes morales de una sociedad, pero no puede servir de criterio para distinguir transgresiones morales peligrosas y no peligrosas. En este sentido, es factible pensar casos en los que el sentimiento de repugnancia e indignación se basan en el prejuicio o en la inercia provocada por una tradición ancestral nunca cuestionada críticamente.

e) Devlin no presenta pruebas empíricas que demuestren que las modificaciones en los hábitos morales de la gente haya conducido a la desintegración de alguna sociedad ${ }^{37}$.

f) Este tipo de posiciones encubren una confusión entre democracia y «populismo moral», es decir, la doctrina de que la mayoría debe determinar no quiénes deben gobernar sino cómo los demás deben vivir ${ }^{38}$.

Abundando en este último punto es necesario clarificar el significado que Lord Devlin, los comunitaristas y el propio Tribunal atribuyen al término «moral». Cuando se habla de moral se puede hacer referencia a dos cosas distintas: la moral positiva y la moral crítica $^{39}$.

\section{La moralidad positiva}

Es aquella que es aceptada y compartida por la mayoría de un determinado grupo social. El elemento básico de la moral compartida o aceptada por un grupo social consiste en reglas primarias de obligación, es decir, reglas que se sustentan en una seria presión social y por el considerable sacrificio de interés o inclinación individual que su cumplimiento trae aparejado.

Hart señala que las reglas que componen la moral social pueden ser distinguidas y clasificadas de maneras diferentes. Por un lado, algunas tienen un ámbito de aplicación restringido que se refiere a una esfera particular de conducta, como por ejemplo, el vestir,

${ }^{37}$ Hart, H. L. A.: Law, Liberty and Morality, op. cit., pág. 50.

${ }^{38}$ Hart, H. L. A.: Law, Liberty and Morality, op. cit. pág. 77 y ss., y también, Nino, C. S.: Introducción al análisis del Derecho. Ariel, Barcelona, 1984, págs. 425-6.

${ }^{39}$ Hart, H. L. A.: Law, Liberty and Morality, op. cit., pág. 20. Ronald Dworkin esboza otra distinción similar en torno a lo que el denomina «posición moral antropológica» y la «posición moral discriminatoria». Dworkin, Ronald: «Libertad y moralismo», op. cit., pág. 358. 
o a actividades para las cuales sólo hay oportunidades discontinuas (ceremonias y juegos). En otros casos, las reglas se aplican sólo a subgrupos sociales, mientras que en otros, al grupo completo. Desde otro punto de vista algunas reglas morales, cuando son transgredidas pueden dar lugar a una simple advertencia, y en otras, a un reproche, a una exclusión o a un desprecio colectivo ${ }^{40}$.

Sin embargo, y esto es lo que importa destacar, dentro del nombre genérico de «moral» se incluyen reglas que se consideran de alguna importancia, y que se aplican a lo que debe hacerse o no hacerse en circunstancias que se suceden con reiteración en la vida social cotidiana. Exigen determinadas y específicas conductas $u$ omisiones, cuya transgresión genera una censura seria.

Las obligaciones y deberes que surgen de esta moral positiva pueden variar de una sociedad a otra, o incluso dentro de la propia sociedad, y también en el transcurso del tiempo. Generalmente, esta variedad viene motivada por las distintas necesidades sentidas en cada sociedad.

Los juicios que se refieren a la moral positiva describen hechos, por lo que no expresan juicios justificatorios en sentido estricto, de acciones o decisiones. Como señala Nino, la moral social es tomada en consideración por el individuo no como razón justificatoria última de sus acciones, sino como razón prudencial para evitar consecuencias que considera desagradables:

«la moral positiva sólo concierne al razonamiento práctico del hombre "prudente", quien está principalmente preocupado por las reacciones sociales que pueden provocar sus actos»» ${ }^{41}$.

\section{La moral crítica}

Se refiere a los principios generales obtenidos reflexivamente por los individuos y que sirven para criticar sus propias acciones como las instituciones sociales y la propia moral positiva ${ }^{42}$.

${ }^{40}$ Hart, H. L. A.: El concepto de Derecho, op. cit., pág. 211.

${ }^{41}$ Nino, C. S.: Ética y derechos humanos, op. cit., pág. 93.

${ }^{42}$ Hart, H. L. A.: Law, Liberty and Morality, op. cit., pág. 20. La defensa de la moral crítica no involucra necesariamente un compromiso con una moral objetiva, absoluta y universal. Puede ser vista como un conjunto de valores y principios que surgen de un proceso reflexivo y justificatorio llevado a cabo por los individuos bajo unos requisitos procedimentales dados: igualdad en el discurso, imparcialidad, universabilidad de los juicios, etc. Por otro lado, estos valores y principios pueden ser comunicados y generar un consenso ideal acerca de su justificación. Ver Pére Luño, A. E.: Derechos humanos, Estado de Derecho y Constitución. Tecnos, Madrid, 1984, pág. 162. 
En contraposición a la moral positiva, la moral crítica corresponde al razonamiento práctico del hombre «moral», es decir, aquel que no se guía por las reacciones sociales de sus juicios éticos, sino por la fuerza justificatoria que está detrás de los actos y decisiones; es decir, su punto de referencia es la moral ideal.

La principal diferencia entre estos dos conceptos de moral estriba en que los juicios de la moral ideal se consideran válidos según ciertas reglas procedimentales y los de la moral positiva aceptados socialmente. No obstante, la relación entre ambos juicios no es excluyente, hay juicios válidos desde el punto de vista de una moral ideal que son vigentes socialmente. Es más, una total asimetría entre los juicios morales ideales es inviable: una moral social se mantiene en la medida en que converge con los juicios morales críticos que la gente está dispuesta a formular ${ }^{43}$.

Esta distinción entre moral positiva y moral ideal tiene importantes consecuencias en la discusión justificatoria según el punto de vista que se sostenga. Así, el liberalismo introduce esta distinción como uno de los elementos centrales de su discurso. La moral ideal es vista como

«un momento de distancia frente a las normas dadas para poder establecer su validez; es necesaria una distancia para establecer la crítica que posibilita el punto de vista moral» ${ }^{44}$.

En cambio, el comunitarismo trata de diluir esta distinción crítica acentuando que toda crítica debe partir y terminar en los valores compartidos de la población: toda crítica moral es interna. Tal posición hace difícil la explicación del cambio en los valores sociales, como también condena toda disidencia y diferencias que vayan en contra de la moral social.

Puede afirmarse que el uso del término «moral» que han utilizado Lord Devlin y el Tribunal Europeo corresponde al sentido «social» o «positivo». La moral que debe ser protegida es aquella que manifiestan los individuos que forman la sociedad, es decir, sus convicciones y actitudes frente a las acciones de sus congéneres. La opinión que debe ser tomada en cuenta es aquella del hombre razonable.

La adopción del Tribunal Europeo de este sentido antropológico de la noción «moral» plantea graves inconvenientes como punto de apoyo justificatorio de sus decisiones. Como señala Dworkin, aunque sea cierto que una comunidad manifieste un tremendo aborreci-

${ }^{43}$ Nino, C. S.: Ética y derechos humanos, op. cit., pág. 93.

${ }^{44}$ Thiebaut, Carlos: Los límites de la comunidad. Centro de Estudios Constitucionales, Madrid, 1993, pág. 159. 
miento a la homosexualidad, también puede ser que dicha opinión no se sustente en ningún argumento racional, sino todo lo contrario, que sea un conglomerado de prejuicios (por ejemplo, que los homosexuales son moralmente inferiores) y de aversiones personales no reflexionadas. En estos casos, es improbable que el «hombre razonable» pueda ofrecer razones autónomas y críticas al respecto.

En estos supuestos, la adhesión únicamente al principio de la mayoría como criterio de resolución de cuestiones morales se presenta como problemático. Los prejuicios y las aversiones personales inherentes en la moralidad positiva no justifican la limitación de ciertos derechos. En la misma línea, el legislador o el juez que debe resolver un problema, y para ello debe percatarse y tener en cuenta la práctica moral generalmente observada, no esta justificado para adherirse a ella acríticamente.

Este punto es especialmente significativo cuando los elementos que se ponen en la balanza son por un lado, la moral positiva, y por el otro lado, los derechos humanos, entendidos como integrantes de la moral crítica. Esta contraposición se ha planteado en varias ocasiones en la jurisprudencia del Tribunal. La solución a todos los casos no ha sido uniforme, sino que su opinión se ha flexibilizado en atención a las circunstancias en juego. Sin embargo, de lo expuesto en las páginas anteriores se extrae como conclusión que es injustificado que las consideraciones basadas en la moral social se antepongan frente a la moral crítica (derechos humanos). Y aquí vale citar la expresión de Dworkin: los derechos humanos son «triunfos» que no ceden frente a razones basadas en criterios numéricos o de utilidad social.

En conclusión, el CEDH parte de una descripción correcta acerca de la falta de homogeneidad moral de las diferentes sociedades que lo componen; es decir, dichas sociedades no sostienen valoraciones y concepciones idénticas de lo bueno. Precisamente el liberalismo es una concepción que trata de solucionar los problemas en que se encuentra una sociedad que da cobijo a diferentes concepciones del bien. El liberalismo supone un reconocimiento de la pluralidad de las creencias y de las concepciones del bien, cuya coexistencia puede lograrse a través de una teoría procedimental de la justicia,

«... y en particular, la primacía de la justicia entre los ideales morales y políticos. $\mathrm{Su}$ tesis central puede ser expresada como sigue: la sociedad, en el sentido de que es un compuesto de una pluralidad de personas con intereses, pretensiones y concepciones del bien diferentes, se organiza mejor cuando está gobernada por principios que no presuponen ellos mismos ninguna concepción del bien; lo que justifica estos principios 
regulativos no es la maximización del bienestar social o la promoción del bien, sino más bien que se conforman al concepto de correcto, una categoría moral prioritaria e independiente del bien ${ }^{45}$.

A pesar de la retirada que han experimentado algunos teóricos del liberalismo a favor de algunas tesis comunitaristas, es preciso mostrar los peligros de la renuncia a la universalidad del discurso moral. El reconocimiento realizado por Rawls del particularismo occidental de su teoría de la justicia no es más que el primer paso hacia el reconocimiento de que el discurso moral sólo se entiende en una sociedad determinada ${ }^{46}$. Pero no hay razón alguna para detener ahí este proceso: alguien podría señalar que en una sociedad coexisten varios grupos sociales con diferentes concepciones y prácticas morales que solo se pueden entender internamente, y así se podría continuar casi indefinidamente.

De hecho esto puede ejemplificarse con la práctica seguida por el TEDH y su concepción de la moral. En principio, los derechos humanos recogidos en el CEDH constituyen el reflejo de la idea liberal de justicia para una comunidad atravesada por diferentes concepciones morales; los derechos humanos son la expresión de un esperanto moral. Pueden concebirse como la concesión mínima que realizan los individuos o los Estados para garantizar la evaluación neutral e imparcial en la esfera pública del desarrollo privado de las respectivas concepciones de lo bueno.

Pero la retirada liberal supone que ante la inexistencia de un concepto o práctica moral europea, el TEDH ha de rebajarse a considerar lo que es moral en cada Estado. Y esto ya esta muy cerca de la «moralidad del patriotismo» de MacIntyre y del riesgo de disolución de la crítica de las prácticas sociales de una comunidad. En definitiva, implica una renuncia a establecer un «orden común de derechos humanos».

Frente a esa tendencia una tarea importante es señalar cuáles son las consecuencias ulteriores de la retirada del universalismo de los derechos humanos. Estas consecuencias se diferencian mucho de los atractivos iniciales que presenta la teoría particularista. De hecho, esta no es una corriente nueva sino que enlaza con la tesis conserva-

${ }^{45}$ Sandel, Michael: Liberalism and the Limits of Justice. Cambridge University Press, Cambridge, 1982, pág. 1.

${ }^{46}$ Rawls, John: «La idea de un consenso por superposición»; en Derecho y Moral. Ensayos analíticos. Betegon, J.-Páramo, J. R. de (eds.). Ariel, Barcelona, 1990. Trad. Juan Carlos Bayón. Pág. 65 [Oxford Journal of Legal Studies, 7 n. ${ }^{\circ}$ 1, 1987]. 
doras. Por ello, y para finalizar este trabajo, es oportuno citar a Brian Barry, quien resume acertadamente las raíces conservadoras del pensamiento comunitarista y sus consecuencias respecto a los derechos humanos:

«La situación actual de los derechos humanos es un tanto irónica. Por un lado vemos que se exige su reconocimiento y puesta en práctica en países como China y Rusia que carecen de una tradición institucional liberal. Por otro, en las democracias liberales, durante los últimos años los filósofos políticos han ido abandonando cada vez más los esfuerzos para apoyar tales demandas, y de hecho han sugerido que cualquier alusión a presuntos principios es inútil y errónea. Comunitaristas como Michael Walzer y Alasdair MacIntyre o pragmatistas como Richard Rorty han llegado desde diferentes ópticas a conclusiones de orden práctico muy similares a las de conservadores en la línea de Burke o Michael Oakeshott: en vez de apelar a principios abstractos debemos apelar al espíritu de las instituciones consolidadas en nuestra propia sociedad.

Los estudiantes de Pekín o los manifestantes de Moscú recibirían malas noticias si fuera verdad que el único argumento válido fuera el recurso a las prácticas propias de cada sociedad. Las peticiones de reforma podrían zanjarse taxativamente con la respuesta siguiente: "el reconocimiento de los derechos humanos no es la practica habitual aquí y nunca lo ha sido"... La tortura, los escuadrones de la muerte o el genocidio nunca pueden justificarse diciendo: "así es como hacemos las cosas aquí"»" 220.

${ }^{47}$ Barry, Brian: «Derechos humanos, individualismo y escepticismo», DOXA, 11, 1992, pág. DOXA 17-18 (1995) 